\title{
SERUM BRAIN DERIVED NEUROTROPHIC FACTOR AS BIOMARKER FOR EPILEPSY DIAGNOSIS IN EGYPTIAN CHILDREN WITH EPILEPSY; RELATIONSHIP TO DISEASE SEVERITY AND COGNITIVE FUNCTION
}

\author{
INAS R EL-ALAMEEY ${ }^{1 *}$, HANAA H AHMED ${ }^{2}$ \\ ${ }^{1}$ Department of Child Health, National Research Centre, Giza, Egypt. ${ }^{2}$ Department of Hormones, National Research Centre, Giza, Egypt. \\ Email: inasno@hotmail.com http://orcid.org/0000-0002-0168-7663
}

Received: 12 August 2017, Revised and Accepted: 16 October 2017

ABSTRACT

Objectives: This study was designed to estimate serum brain-derived neurotrophic factor (BDNF) concentration in a group of Egyptian children with epilepsy to clarify its utility as a biomarker for epilepsy diagnosis and to evaluate its relationship with their cognitive function and disease severity.

Methods: Intelligence was assessed using Arabic version of the WISC-R test. Serum concentration of BDNF was assessed using enzyme-linked immunosorbent assay in 40 children with epilepsy and 40 apparently healthy children of matched age and sex controls.

Results: Of total 40 epileptic patients aged 6-12 years, the mean age was $8.32 \pm 0.7$ years and male to female ratio was $1.5: 1$. The mean serum BDNF concentration and cognitive IQ scores were statistically significantly reduced in the studied patient's group versus to controls ( $\mathrm{p}<0.001$ ). There were highly significant differences in serum BDNF concentration as regards epileptic severity. Serum concentration of BDNF showed significantly positive correlation with cognitive, verbal, performance, and totals IQ scores and negative correlation with the age at the onset of seizures, and duration of therapy. The linear regression analysis showed a statistically significant association between age at the onset of seizures, duration of therapy, cognitive function, and serum BDNF concentrations among the studied patients.

Conclusions: Concentration of BDNF in serum is involved in the mechanism of epileptogenesis in children with epilepsy. It should be used as a helpful marker for epilepsy diagnosis and detection of severity.

Keywords: Epilepsy, Brain-derived neurotrophic factor, Egyptian children, Cognitive function, Disease severity.

(C) 2018 The Authors. Published by Innovare Academic Sciences Pvt Ltd. This is an open access article under the CC BY license (http://creativecommons. org/licenses/by/4. 0/) DOI: http://dx.doi.org/10.22159/ajpcr.2018.v11i1.21961

\section{INTRODUCTION}

Epilepsy is one of the most common chronic neurological diseases in children, which is manifested by a sudden transient disturbance of brain function [1]. It is often associated with changes or loss of consciousness that have a burden insult on the cognitive function of epileptic children [2]. At school age, the prevalence of epilepsy is between 4 and $7 / 1000$ children [3].

Brain-derived neurotrophic factor (BDNF) is one of the neurotrophin family of growth factors promoting neuronal differentiation, neurogenesis, and neural plasticity [4,5]. It is found throughout the brain, particularly in the cerebral cortex and hippocampi. The dysregulation of BDNF leads to a number of neurologic and psychiatric disorders [6].

BDNF concentration was found to be elevated in brain tissues of children with resistant temporal lobe epilepsy [7]. Kanemoto et al. [8] also demonstrated a relation between BDNF gene polymorphism and partial epilepsy. Otherwise, BDNF serum concentration in epileptic children has not been previously well described. Therefore, the aim of our present study was to compare serum BDNF concentration in a group of Egyptian children with epileptic seizures between epileptic attacks and healthy controls to assess its utility as a diagnostic tool and evaluate its relationship with their cognitive function, and disease severity.

\section{METHODS}

Design and setting of the study

This descriptive comparative case-control study was conducted on 40 patients with epilepsy over a period of 2 years (from March 2013 to February 2015). They referred to the Center of Excellence, National Research Centre (NRC) in Egypt from the outpatient epilepsy, Clinic Abu Elrich Hospital, for assessment of their cognitive function.

\section{Patients}

Epilepsy was defined as the separate occurrence of two or more unprovoked seizures, manifested by involuntary motor, sensory, or autonomic, alone or in combination, and not diagnosed as neonatal or febrile seizures $[9,10]$. Epileptic children were examined by a pediatric neurologist. The diagnosis of epilepsy in the children was made on the basis of history and confirmed by video-electroencephalogram (EEG) monitoring. They were diagnosed according to the international classification of epileptic seizures, epilepsies, and epileptic syndromes of league against epilepsy for the determination of seizure types, epilepsy disorders, and age-specific epileptic syndromes [11]. Children with epilepsy were also assigned to subgroups with regard to epilepsy type (generalized/partial), drug therapy (poly/monotherapy). Our study was conducted on 80 children; 40 children with epilepsy and 40 apparently healthy children with no chronic illness of matched age, sex, and social class as controls. They were selected from the outpatients Child Health Clinic at the NRC. They were attending the Clinic for follow-up.

Cases included in this study were randomly selected among children who recently had seizures over a period of 1 year. Exclusion criteria were (i) a history of epilepsy surgery, (ii) a history of psychogenic seizures or uncertain diagnosis, (iii) presence of an active neurological disorder, and (iv) active comorbid psychiatric illness.

\section{Controls}

Age, sex, and social class matched 40 apparently healthy children without CHD were included as the control group. They were selected 
from the outpatients' Clinic at NRC while they were coming for follow up.

\section{Standard protocol approvals and consents}

This study was approved by the Research Ethics Committee of the NRC with Ethics Committee Number 17082. All studied cases provided signed written consent form of the Medical Ethical Committee of NRC to participate in the assessments from the parents of the children before study enrollment.

\section{Methods}

\section{Assessments}

- Epilepsy severity assessment

All patients were subjected to a detailed assessment of history including a detailed description of the epilepsy severity variables including age at the onset of seizures, type of epilepsy, duration of seizures, its frequency, duration of therapy, and the degree of control upon treatment.

- Intellectual assessment

Cognitive abilities were assessed by the administration of the Arabic version of the WISC-R [12]. It is the most widely used scale to assess the intelligence of children aged between 6 and 15 years, and it takes around $1.5 \mathrm{~h}$. It provides scores for verbal, performance, and full-scale IQ score. Its subtests include different types of tasks, allowing the observation of the child's strengths, and weaknesses. Results from IQ tests help guide diagnosis, treatment, and educational planning. The average or normal IQ for children ranged from 90 to 110 .

\section{Laboratory diagnosis}

After an overnight fast, venous blood samples were collected from all participants and the separated sera were stored at $-20^{\circ} \mathrm{C}$. Quantitative determination of BDNF concentration in serum samples was performed using enzyme-linked immunosorbent assay kit purchased from Glory Bioscience, USA, according to manufacturer's instructions.

\section{Statistical analysis}

All analyses were performed using the statistical package for the social sciences (SPSS), version 22 computer program (SSPS Inc, Chicago, USA), and the results were presented as Tables and Figures. Quantitative variables are expressed as the mean $\pm \mathrm{SD}$. The sample size was calculated to assess the risk factors probably affecting serum BDNF concentration of children with epilepsy between attacks. To compare cognitive score and serum BDNF concentration between groups, Student's t-test was used. Categorical data were expressed as frequencies and percentages and analyzed with the two-tailed Chi-square test. Pearson's correlation coefficient was used to assess for association between serum BDNF concentration, cognitive scores, and seizures' variables. As the concentration of BDNF has a normal distribution, linear regression analysis was used to estimate the effects of different risk factors as duration of therapy with antiepileptic medications (years), age of the onset of seizures, and IQ scores in potentially changing the BDNF concentrations. $p<0.05$ was considered significant and $p<0.001$ was considered highly significant.

\section{RESULTS}

Demographic data and characteristics of the participants

A total number of 40 epileptic patients ( $60 \%$ males and $40 \%$ females) were enrolled in this study, giving a male to female ratio of 1.5:1 and a significant sex distribution $(\mathrm{p}<0.05)$. The patients' age ranged from 6 to 12 years with a mean of $8.32 \pm 0.7$ years. Generalized tonic-clonic seizures were seen in $50 \%$ epileptic children being treated with polytherapy while partial seizures were diagnosed in $50 \%$ children being treated with monotherapy. 16 patients $(40 \%)$ had severe epilepsy, as indicated by a seizure frequency of more than one attack per month, and $24(60 \%)$ of patients were controlled. The therapeutic period ranged from 2 to 6.5 years with a mean of $3.63 \pm 1.53$ years (Table 1).
Serum BDNF concentration in controls and children with epilepsy The mean serum concentration of BDNF was significantly lower in the studied patient's group $(6.93 \pm 0.34 \mathrm{ng} / \mathrm{ml})$ compared to controls $(8.08 \pm 0.56 \mathrm{ng} / \mathrm{ml})(\mathrm{p}<0.001)$, as shown in Fig. 1 and Table 2. The mean cognitive, verbal, performance, and total IQ scores showed highly significantly lower in patients relative to control group $(p<0.001)$ as shown in Table 2.

Relation of serum BDNF concentration to types of seizures and seizures frequencies

The mean concentration of serum BDNF showed insignificant differences between generalized epilepsy and partial epilepsy ( $p>0.05)$.

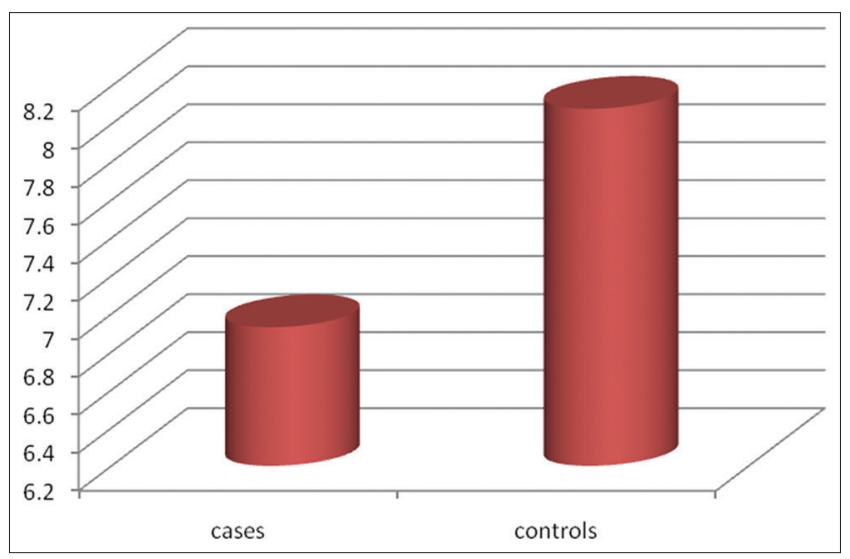

Fig. 1: Comparison of serum brain-derived neurotrophic factor concentration $(\mathrm{ng} / \mathrm{ml})$ between the studied cases and control group

Table 1: Demographic data and clinical characteristics of the studied patients

\begin{tabular}{lll}
\hline Variables & Mean \pm SD & Range \\
\hline Gender (\%) & Male & $60 \%$ \\
& Female & $40 \%$ \\
Age (years) & $8.32 \pm 0.7$ & $6-12$ \\
Age at the onset of symptoms & $1.18 \pm 0.73$ & $0.3-2.5$ \\
Duration of therapy & $3.63 \pm 1.53$ & $2-6.5$ \\
Seizure frequency & $\mathrm{n}$ & Percent \\
Controlled & 24 & 60 \\
$\quad$ Uncontrolled & 16 & 40 \\
Types of seizures & & \\
Generalized & 20 & 50 \\
Partial & 20 & 50 \\
\hline
\end{tabular}

Table 2: Comparison of serum BDNF concentration and cognitive variables between the studied patients and control group

\begin{tabular}{|c|c|c|c|c|}
\hline Variables & Cases & Controls & $\mathbf{t}$ & p value \\
\hline \multicolumn{5}{|c|}{ Serum BDNF (ng/ml) } \\
\hline Mean $\pm S D$ & $6.93 \pm 0.34$ & $8.08 \pm 0.56$ & -7.41 & $0.00^{* *}$ \\
\hline Range & $6.3-7.2$ & $7.4-8.9$ & & \\
\hline \multicolumn{5}{|c|}{ Verbal IQ score } \\
\hline Mean $\pm S D$ & $83.5 \pm 3.2$ & $95.8 \pm 6.4$ & -9.46 & $0.00^{* *}$ \\
\hline Range & $79-88$ & $90-108$ & & \\
\hline \multicolumn{5}{|c|}{ Performance IQ score } \\
\hline Mean \pm SD & $79 \pm 11.32$ & $91.3 \pm 2.54$ & -3.3 & $0.009 * *$ \\
\hline Range & $57-89$ & $88-96$ & & \\
\hline \multicolumn{5}{|c|}{ Total IQ score } \\
\hline Mean \pm SD & $81 \pm 6.96$ & $93.5 \pm 3.1$ & -7.26 & $0.00^{* *}$ \\
\hline Range & $68-88$ & $90-99$ & & \\
\hline
\end{tabular}

**Highly significant difference at $\mathrm{p}<0.001$, BDNF: Brain-derived neurotrophic factor 
However, there was highly significant association between serum BDNF concentration and disease severity $(\mathrm{p}<0.05)$ as shown in Table 3 .

\section{Relation of serum BDNF concentration to patients' gender} Insignificant differences in serum BDNF concentration were found between female and males patients ( $p>0.05)$, as shown in Table 3 .

\section{Serum BDNF concentration related to epilepsy risk factors}

Serum concentration of BDNF showed significant positive correlation with cognitive, verbal, performance, and total IQ scores and negative correlation with duration of therapy with antiepileptic drugs, and the age at the onset of seizures (Table 4).

The linear regression analysis showed a statistically significant association between serum BDNF concentration and early disease onset, long duration of therapy with antiepileptic medications, as well as low cognitive function (total, verbal, and performance IQ scores) among the studied patients $(\mathrm{p}<0.01)$ as shown in Table 5 .

\section{DISCUSSION}

The importance of BDNF stems from its functions as a regulator of neuronal survival, growth and differentiation, connectivity during development in addition to its role in synaptic plasticity [13]. Recently, it has been found that decreased plasma BDNF level in adults is reduced with epileptic seizures [14], while serum BDNF concentration in children with epilepsy has not been previously well described. Connolly et al. [15] recorded no differences in serum BDNF concentrations between epileptic children and controls. Therefore, the purpose of our

Table 3: Comparison of serum BDNF concentration as regards gender, type of seizures, and disease severity

\begin{tabular}{|c|c|c|c|}
\hline \multirow[t]{2}{*}{ Variables } & $\begin{array}{l}\text { Serum BDNF } \\
\text { concentration }(\mathrm{ng} / \mathrm{ml})\end{array}$ & \multirow[t]{2}{*}{ Chi-square } & \multirow[t]{2}{*}{ p value } \\
\hline & Mean \pm SD & & \\
\hline \multicolumn{4}{|l|}{ Gender } \\
\hline Female & $6.97 \pm 0.28$ & 0.822 & 0.43 \\
\hline Male & $6.75 \pm 0.63$ & & \\
\hline \multicolumn{4}{|l|}{ Type of seizures } \\
\hline Generalized & $6.73 \pm 0.28$ & 0.78 & 0.35 \\
\hline Partial & $6.97 \pm 0.63$ & & \\
\hline \multicolumn{4}{|l|}{ Disease severity } \\
\hline Controlled & $7.12 \pm 0.07$ & 7.8 & $0.00 * *$ \\
\hline Uncontrolled & $6.46 \pm 0.2$ & & \\
\hline
\end{tabular}

study was to elucidate the potential use of BDNF in early diagnosis of epilepsy by determining serum BDNF concentrations in children with epilepsy and compare with the healthy controls between epileptic attacks to clarify its utility as a biomarker for epilepsy diagnosis and severity.

Forty epileptic patients, $60 \%$ males and $40 \%$ females, were recruited into this study giving a male to female ratio of $1.5: 1$ and a significant sex distribution $(\mathrm{p}<0.05)$. This is in respect with the findings of Shinnar and Pellock [16], who mentioned that the frequency rate is higher in males $(63.6 \%)$ than females $(36.4 \%)$, with a male to female ratio of 1.9:1.

The age of our patients ranged from 6 to 12 years with a mean of $8.32 \pm 0.7$ years. 16 patients $(40 \%)$ of the children were controlled meaning that they had severe epilepsy, as defined by a seizure frequency of more than one attack per month, and $24(60 \%)$ of patients were controlled. The duration of therapy with antiepileptic drugs ranged from 2 to 6.5 years with a mean of $3.63 \pm 1.53$ years.

Epileptic children are more likely to have cognitive dysfunction than normal children [17-19]. In our present study, the mean cognitive, verbal, performance, and total IQ scores were statistically highly significantly lower in patients versus control group $(\mathrm{p}<0.001)$. Learning disabilities in our study as in previous reports [19-21] may be due to multifactor acting individually or synergistically. These include the detrimental effects of antiepileptic drugs and repeated seizures on the developing brain.

Our results showed that the mean serum concentration of BDNF was statistically significantly lower in the studied patient's group $(6.93 \pm 0.34 \mathrm{ng} / \mathrm{ml})$ compared to controls $(8.08 \pm 0.56 \mathrm{ng} / \mathrm{ml})(\mathrm{p}<0.001)$. This is in agreement with Waragai et al. [22] who reported that BDNF concentration in plasma is significantly reduced in patients with epilepsy relative to controls. There are interesting documents for the implication of the neurotrophin BDNF in the pathogenesis of epilepsy. However, our results are not in agreement with Connolly et al., [15] who observed no difference in BDNF concentration between children with epilepsy and controls.

In our present study, the effect of different risk factors (i.e., gender, seizures frequency, severity, age at the onset of epileptic seizures, and duration of therapy with antiepileptic drugs) on the potential changes in serum BDNF concentration was detected. There are no significant differences in the mean of the serum BDNF concentration between female and male patients $(p>0.05)$. Our results are in the agreement with Erickson et al. [23], Ziegenhorn et al. [24], and Yasutake et al. [25], who mentioned that BDNF concentration does not display any significant gender difference.

Table 4: Correlation between age at the onset of seizures, duration of therapy, and IQ scores with serum BDNF concentration

\begin{tabular}{|c|c|c|c|c|c|}
\hline Variables & Age at the onset of seizures & Duration of therapy & Verbal IQ scores & Performance IQ scores & Total IQ scores \\
\hline \multicolumn{6}{|c|}{ Serum BDNF (ng/ml) } \\
\hline $\mathrm{r}$ & $-0.67^{*}$ & -0.76 & $0.485^{* *}$ & $0.528 * *$ & $0.547 * *$ \\
\hline $\mathrm{p}$ & 0.034 & 0.11 & 0.001 & 0.000 & 0.000 \\
\hline
\end{tabular}

*Significant difference at $\mathrm{p}<0.05,{ }^{* *}$ highly significant difference at $\mathrm{p}<0.01$, BDNF: Brain-derived neurotrophic factor

Table 5: Linear regression analysis of risk factors associated with serum BDNF concentrations among the studied patients

\begin{tabular}{|c|c|c|c|c|c|c|}
\hline \multirow[t]{2}{*}{ Variables } & \multicolumn{2}{|c|}{ Unstandardized coefficients } & \multirow{2}{*}{$\begin{array}{l}\text { Standardized coefficients } \\
\text { Beta }\end{array}$} & \multirow[t]{2}{*}{ p value } & \multicolumn{2}{|c|}{$95 \%$ confidence interval } \\
\hline & B & Standard error & & & Lower bound & upper bound \\
\hline Constant & 5.762 & 0.835 & & 0.00 & 4.064 & 7.46 \\
\hline Long duration of therapy & 0.126 & 0.024 & 0.568 & $0.00 * *$ & 0.173 & 0.078 \\
\hline Verbal IQ score & 0.089 & 0.044 & 0.868 & $0.049^{*}$ & 0.001 & 0.178 \\
\hline Performance IQ score & 0.120 & 0.043 & 3.912 & $0.009 * *$ & 0.032 & 0.209 \\
\hline Total IQ score & 0.207 & 0.086 & 4.155 & $0.022^{*}$ & 0.381 & 0.032 \\
\hline
\end{tabular}

Dependent factor: BDNF concentration. *Significant difference at $\mathrm{p}<0.05, * *$ highly significant difference at $\mathrm{p}<0.01$, BDNF: Brain-derived neurotrophic factor 
In the current study, the mean concentration of serum BDNF showed insignificant differences between generalized epilepsy and partial epilepsy ( $p>0.05$ ). These results come in line with those previously published by LaFrance et al. [17].

According to data obtained in our study, serum concentration of BDNF showed significant positive correlation with cognitive, verbal, performance, and total IQ scores $(\mathrm{p}<0.001)$. This is in agreement with Angelucci et al. [26] and Forlenza et al. [27] who reported that serum BDNF concentration is considered as a key player in the activitydependent synaptic plasticity that is involved in the learning and memory processes.

The other observation in the current study was the significant association between low serum BDNF concentration and low cognitive function among the studied patients with epilepsy by linear regression analysis $(\mathrm{p}<0.001)$. This is in agreement with Unalpa et al. [28].

The association between epilepsy severity and serum BDNF concentration was investigated. The present findings suggested that serum BDNF might have a benefit as a biomarker of epilepsy severity, as there were highly significant differences in serum BDNF concentration as regards epilepsy severity (determined by seizure frequency) $(\mathrm{p}<0.001)$. Furthermore, serum BDNF concentration was negatively correlated with epilepsy severity (determined by age at onset of seizures and duration of antiepileptic therapy). These findings are in agreement with Unalpa et al. [28] who reported that a decreased serum BDNF is correlated with epilepsy severity.

The other observation in the current study was the significant association between serum BDNF concentration and early disease onset, long duration of antiepileptic therapy among the studied patients with epilepsy by linear regression analysis $(p<0.001)$ which is in concert with the report from Unalpa et al. [28].

In conclusion, our data proved the significant decline in serum BDNF concentration and cognitive IQ scores in the epileptic children compared to control counterparts. Therefore, along with video-EEG, serum BDNF concentration should be used as a helpful biomarker for epilepsy diagnosis and severity.

\section{ACKNOWLEDGMENT}

Special appreciations go to Abu Elrich Hospital staff for scientific collaboration

\section{AUTHORS CONTRIBUTION:}

Inas R. EL-Alameey: responsible for concept, collection of samples, analysis and interpretation of data; drafting and revising of the manuscript. Hanaa H. Ahmed: responsible for biochemical analysis, interpretation of data and revising of the manuscript.

\section{CONFLICTS OF INTERESTS}

The authors declare that they have no conflict of interest.

\section{REFERENCES}

1. Arulsamy A, Goh BH, Shaikh MF. Current status of epilepsy in Malaysia and way ahead. Int J Pharm Pharm Sci 2015;7:2-5.

2. Berg AT, Berkovic SF, Brodie MJ, Buchhalter J, Cross JH, van Emde Boas W, et al. Seizures and epilepsy in children: Classification, etiology, and clinical features. Epilepsia 2010;51:676.

3. Russ SA, Larson K, Halfon N. A national profile of childhood epilepsy and seizure disorder. Pediatrics 2012;129:256-64.

4. Tapia-Arancibia L, Rage F, Givalois L, Arancibia S. Physiology of BDNF: Focus on hypothalamic function. Front Neuroendocrinol
2004;25:77-107.

5. Scharfman HE. Brain-derived neurotrophic factor and epilepsy-a missing link? Epilepsy Curr 2005;5:83-8

6. Binder DK, Scharfman HE. Brain-derived neurotrophic factor. Growth Factors 2004;22:123-31.

7. Murray KD, Isackson PJ, Eskin TA. Altered mRNA expession for brain-derived neurotrophic factor and Type II calcium/calmodulinedependent protein kinase in the hippocampus of children with intractable temporal lobe epilepsy. J Comp Neurol 2000;418:411-22.

8. Kanemoto K, Kawasaki J, Tarao Y. Association of partial epilepsy with brain-derived neurotrophic factor [BDNF] gene polymorphism. Epilepsy Res 2003;53:255-8.

9. Fisher RS, Acevedo C, Arzimanoglou A, Bogacz A, Cross JH, Elger CE, et al. ILAE official report: A practical clinical definition of epilepsy. Epilepsia 2014;55:475-82

10. International League Against Epilepsy Commission on Classification and Terminology of the International League Against Epilepsy. Proposal for revised classification of epilepsies and epileptic syndromes. Epilepsia 1993; 34:592-596.

11. Sarma P, Bhattacharyya A. Models of epilepsy used in antiepileptic drug discovery. Int J Pharm Pharm Sci 2014;6:1-7.

12. Wechsler D. Manual for the Wechsler Intelligence Scale for ChildrenRevised. $4^{\text {th }}$ ed. [WISC-IVs]. 20. San Antonio, Texas: The Psychological Corporation; 2008. p. 377-84.

13. Huang EJ, Reichardt LF. Neurotrophins: Roles in neuronal development and function. Annu Rev Neurosci 2001;24:677-736.

14. Hong Z, Li W, Qu B, Zou X, Chen J, Sander JW, et al. Serum brain-derived neurotrophic factor levels in epilepsy. Eur J Neurol 2014;21:57-64.

15. Connolly AM, Chez M, StreifEM, Keeling RM, Golumbek PT, Kwon JM, et al. Brain-derived neurotrophic factor and autoantibodies to neural antigens in sera of children with autistic spectrum disorders, LandauKleffner syndrome, and epilepsy. Biol Psychiatry 2006;59:354-63.

16. Shinnar S, Pellock JM. Update on the epidemiology and prognosis of pediatric epilepsy. J Child Neurol 2002;17 Suppl 1:S4-17.

17. LaFrance WC Jr, Leaver K, Stopa EG, Papandonatos GD, Blum AS. Decreased serum BDNF levels in patients with epileptic and psychogenic nonepileptic seizures. Neurology 2010;75:1285-91.

18. Berg AT, Langfitt JT, Testa FM, Levy SR, DiMario F, Westerveld M, et al. Global cognitive function in children with epilepsy: A communitybased study. Epilepsia 2008;49:608-14.

19. El-Alameey IR, Monir ZM, Eltahlawy E. Neuropsychological problems among Epileptic children in Egypt. Med Res J 2013;12:58-68.

20. Fatenau PS, Jianzhao SH, Dunn DW, Austin JK. Academic performance in children with epilepsy. J Learn Disabil 2008;41:195-207.

21. Ibekwe RC, Ojinnaka NC, Iloeje SO. Factors influencing the academic performance of school children with epilepsy. J Trop Pediatr 2007;53:338-43

22. Waragai M, Wei J, Fujita M, Nakai M, Ho GJ, Masliah E, et al. Increased level of DJ-1 in the cerebrospinal fluids of sporadic Parkinson's disease. Biochem Biophys Res Commun 2006;345:967-72.

23. Erickson KI, Prakash RS, Voss MW, Chaddock L, Heo S, McLaren M, et al. Brain-derived neurotrophic factor is associated with age-related decline in hippocampal volume. J Neurosci 2010;30:5368-75.

24. Ziegenhorn AA, Schulte-Herbrüggen O, Danker-Hopfe $H$, Malbranc M, Hartung HD, Anders D, et al. Serum neurotrophins-a study on the time course and influencing factors in a large old age sample. Neurobiol Aging 2007;28:1436-45.

25. Yasutake C, Kuroda K, Yanagawa T, Okamura T, Yoneda H. Serum BDNF, TNF-alpha and IL-1beta levels in dementia patients: Comparison between Alzheimer's disease and vascular dementia. Eur Arch Psychiatry Clin Neurosci 2006;256:402-6.

26. Angelucci F, Spalletta G, di Iulio F, Ciaramella A, Salani F, Colantoni L, et al. Alzheimer's disease (AD) and Mild Cognitive Impairment (MCI) patients are characterized by increased BDNF serum levels. Curr Alzheimer Res 2010;7:15-20.

27. Forlenza OV, Diniz BS, Teixeira AL, Ojopi EB, Talib LL, Mendonça VA, et al. Effect of brain-derived neurotrophic factor Val66Met polymorphism and serum levels on the progression of mild cognitive impairment. World J Biol Psychiatry 2010;11:774-80.

28. Unalpa A, Bayram E, Ulusoy S, Uran N, Bayram M, Aydog an A, et al. Serum concentration of brain-derived neurotrophic factor in epileptic children. J Pediatr Neurol 2009; 7:251-5. 